\title{
EDITORIAL
}

\section{Avances en la indización de la Revista Virtual de Sociedad Paraguaya de Medicina Interna}

\section{Advances in the indexing of the Virtual Journal of the Paraguayan Society of Internal Medicine}

\section{Estimados lectores,}

en julio de 2019 el sitio web SciELO Paraguay fue evaluado con diversos parámetros y sus revistas aprobaron los criterios de calidad para acceder al portal de SciELO.org. Con este paso los artículos publicados en la Rev Virtual SPMI y otras revistas paraguayas indexadas han dado un gran salto para mejorar la visibilidad a nivel global. Este hecho es trascendente pues permitirá a los lectores de todo el mundo la recuperación rápida de los artículos de la producción científica paraguaya.

También desde inicios de diciembre del 2019 el sitio SciELO Paraguay se halla indexada en la Web of Science. Este es un servicio en línea de información científica, suministrado por Thomson Reuters, que facilita el ingreso a bases de datos en las que aparecen citas de artículos de revistas científicas y acceso a las publicaciones a través de sus referencias bibliográficas citadas, permitiendo describir el impacto de un trabajo científico.

Además, desde este año se puede acceder a las métricas de publicación de cada revista. En ella resalta que la Rev Virtual SPMI ha aumentado progresivamente el número de accesos y descargas en pdf de sus artículos. El Consenso Paraguayo de Hipertensión Arterial ${ }^{(1)}$ fue el artículo con mayores descargas hasta la fecha, señalando el interés de nuestros lectores en información actualizada y de relevancia.

Si bien la mayoría de los autores son paraguayos, una gran parte de los colaboradores son latinoamericanos, demostrando el alcance internacional de nuestros lectores. Muchos artículos de la Rev Virtual SPMI ya fueron citados en revistas norteamericanas y europeas lo que le permitirá ir aumentado en su factor de impacto.

A 6 años de iniciada la publicación de la revista oficial de la Sociedad Paraguaya de Medicina Interna, auguramos éxitos para la misma y nuestros autores y lectores.

\author{
Mag. Prof. Dr. Raúl Real \\ Editor
}

Correo electrónico: raulemilioreal@gmail.com

\section{REFERENCIAS BIBLIOGRÁFICAS}

1. Ortellado Maidana J, Ramírez A, González G, Olmedo Filizzola G, Ayala de Doll M, Sano M, et al. Consenso paraguayo de hipertensión arterial 2015. Rev. virtual Soc. Parag. Med. Int [Internet]. 2016 Sep [citado 20 Nov 2019]; 3(2): 11-57. Disponible en: http://scielo.iics.una.py/pdf/spmi/v3n2/ v3n2a02.pdf. 